\title{
Pyrocarbon Interposition Wrist Arthroplasty in the Treatment of Failed Wrist Procedures
}

\author{
Philippe Bellemère, M.D. ${ }^{1}$ Catherine Maes-Clavier, M.D. ${ }^{1}$ Thierry Loubersac, M.D. ${ }^{1}$ \\ Etienne Gaisne, M.D. ${ }^{1}$ Yves Kerjean, M.D. ${ }^{1}$ Sylvie Collon, M.D. ${ }^{1}$
}

\author{
${ }^{1}$ Nantes Assistance Main, Hand and Upper Limb Surgery Unit, Clinique \\ Jeanne d'Arc, Nantes, France \\ J Wrist Surg 2012;1:31-38.
}

\begin{abstract}
Address for correspondence and reprint requests Philippe Bellemère, M.D., Hand and Upper Limb Surgery Unit, Nantes Assistance Main, Clinique Jeanne d'Arc, 21 rue des Martyrs, 44100, Nantes, France (e-mail: philippe.bellemere@me.com).
\end{abstract}

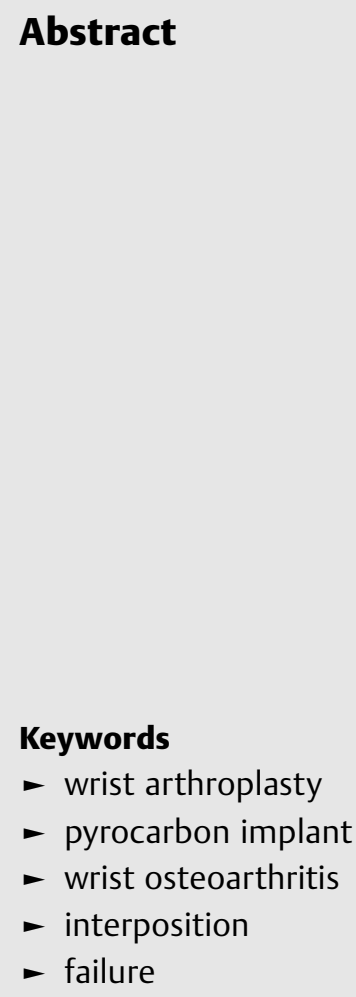

Treatment of failures after prior wrist surgeries with major articular destruction is challenging. In most cases, total wrist fusion is the only possible salvage procedure. We propose a new interposition arthroplasty with a pyrocarbon implant called Amandys.

A total of 16 patients, 14 men and 2 women, with a mean age of 56 years were operated on for a failure of wrist surgery performed previously, with an average time lapse of 12 years. The prior surgeries were partial wrist arthrodesis in seven cases, silicone implant interpositions in five cases, advanced Kienböck disease (Lichtman IV) treatment in two cases, proximal row carpectomy in one case, and an isolated scaphoidectomy in one case. A prospective study with clinical and radiological evaluation was performed with a mean follow-up of 24 months (6 to 41 months).

Pain and function showed significant improvement. The mean pain score decreased from 7 of 10 to 4 of 10 , postoperatively. The mean grip strength was $19 \mathrm{~kg}$ (53\% of the contralateral side), and the mean range of motion in flexion extension was 68 degrees. Mean strength and range of motion did not change significantly with the operation. The mean QuickDASH (Disability Arm Shoulder and Hand) score decreased from 59 of 100 to 39 of 100. The mean Patient-Rated Wrist Evaluation decreased from 57 of 100 to 33. Two patients $(12.5 \%)$ required revision for implant repositioning. No dislocation or subsidence of the implant was noted.

Pyrocarbon interposition arthroplasty is a new option for treatment of advanced wrist destruction. Preliminary short-term results suggest that it may be a reliable alternative to total wrist fusion. The level of evidence of this study is IV (therapeutic case series).
Performing a wrist interposition arthroplasty after a bony resection is an old concept. Ollier had described its principles as early as the late 18th century: the use of an interposition intended to avoid bone fusion after an arthroplastic resection. ${ }^{1}$ Only autologous regional fibrous tissue (capsule, anterior annular ligament) has been recently used in arthroplastic resections of rheumatoid wrists. $^{2-4}$ Today, new concepts of arthroplastic interposition arise with improved knowledge of anatomy and wrist biomechanics, as well as the use of new biomaterials such as pyrocarbon. ${ }^{5}$
Pyrocarbon, with its mechanic and biotolerance characteristics (low friction coefficient, wear resistance, density and elastic module close to those of cortical bone, and lack of osteointegration), is today an ideal material for an interposition implant.

The recent use of pyrocarbon implants in the wrist and thumb base has proven its medium-term reliability and validated the free interposition concept as a means for arthroplasty. $^{6-10}$

Very recently, a new pyrocarbon interposition implant, the Amandys (Tornier SAS-Bioprofile, Grenoble, France), has 
been proposed in an extensive articular destructions of the wrist as an alternative to more radical or invasive surgical options such as total wrist fusion (TWF) or total wrist arthroplasty (TWA). ${ }^{11}$

The concept of the Amandys arthroplasty is that of a free interposition radiocarpal and midcarpal spacer implant made out of pyrocarbon. It replaces the lunate, the two proximal thirds of the scaphoid, and the head of the capitate. It is a mobile spacer with no bone fixation, thus avoiding peak constraint forces on the radius or the carpus. It restores the congruency with the radius and with the distal carpal row. The implant is quadric elliptic in shape. Its proximal ellipsoid curves are perpendicular to one another and are close to the proximal anatomical curves of the scaphoid and lunate, thus achieving optimal congruency with the radial fossa surface.

The two distal curves are less pronounced than the proximal ones. The implant has three main axes: an anteroposterior one, corresponding to its width; a transverse one, corresponding to its length; and a proximal distal one, corresponding to its thickness. The implant exists in eight sizes varying in length ( 24 to $26 \mathrm{~mm}$ ) and in thickness ( $\mathrm{S}, \mathrm{M}, \mathrm{L}$, and $\mathrm{XL}$ ).

The bony surfaces in contact with the implant can glide, roll, and even slightly rotate, especially the carpal surface of the implant, which is less convex than the radial one.

Thanks to minimal bony resection and to the preservation of the triquetrum and the distal third of the scaphoid, an arthroplasty performed with this implant spares the main extrinsic wrist ligaments such as the dorsal radiocarpal ligament, the dorsal intercarpal ligament, and volarly the triquetrohamate ligament and the radioscaphocapitate ligament. $^{12}$ These ligaments play an important part in the kinematics and the stability of the wrist in several movements and especially in the dart-throwing motion. ${ }^{13}$

The instrumentation includes an ovoid burr, a curved periosteal elevator, a corkscrew extractor, and eight trial implants.

\section{Patients and Methods}

Since November 2008, a prospective study was performed on a consecutive series of 16 patients complaining of pain and functional impairment of their wrist due to extensive joint damage following a prior surgery.

The series included 14 men and 2 women with an average age of 56 years (38 to 77 years). The dominant side was involved in eight cases. Ten patients were working at the time of the surgery. Before surgery, all patients had standard posteroanterior (PA) and lateral radiographs and a wrist computed tomography scan or arthroscan.

The mean delay from the first surgery was 11 years and 10 months (13 months to 32 years).

The mean follow-up after the pyrocarbon arthroplasty was 24 months (6 to 41 months).

Indications for surgery for prior failed surgery included the following:

In seven cases, the major indications were partial arthrodesis with nonunion (four cases), major osteoarthritic degra- dation of the radiocarpal (two cases), or midcarpal joints (one case). The seven initial procedures were four scaphoidectomies with a four-bone fusion (-Fig. 1), a scaphoidectomy with a capitolunate arthrodesis, a radiolunate arthrodesis, and a radioscapholunate arthrodesis.

In five cases, the major indications were carpal silicone synovitis with extensive wear of the radiocarpal and midcarpal joints following partial silicone implants (two for the lunate, two for the scaphoid, and one for the trapezium)

\section{(-Fig. 2).}

In two cases, the major indications were advanced Kienböck disease (Lichtman stage IV) that had already undergone a radial shortening.

In one case, a proximal row carpectomy, and in another case, an isolated scaphoidectomy were previously performed.

Contraindications for this arthroplasty were distal radial malunions, radiocarpal or midcarpal instability, major bone loss, incompetent musculotendinous wrist extensors or flexors, and ongoing infection.

\section{Operative Technique}

The procedure was done under local or regional anesthesia with a tourniquet on the proximal part of the arm. The arthroplasty can be performed through a dorsal or a radial approach. ${ }^{11}$ In cases of a failed previous procedure on the wrist, only the dorsal approach was used.

The previous skin incision was used and extended distally or proximally as necessary. The dorsal extensor retinaculum was incised on the radial or ulnar side of the fourth extensor compartment to preserve ligament tissue if a capsular reinforcement was needed at the end of the procedure.

Either a midline or ligament sparing capsulotomy was used. $^{14}$

All previous material (pins, staples, screws, plates, and implant) were removed before any procedure on the joint.

The carpal bone resection was performed after lysis of any adhesions and a synovectomy. First, the two proximal third of the scaphoid were removed with an oscillating saw just above the ligament insertions of the dorsal radiocarpal ligament and the radioscaphocapitate ligament, which must be preserved. The cut was parallel to the frontal and transversal slopes of the radial fossa.

The lunate was then freed from all ligamentous attachments. The corkscrew was used as a joystick during this step to preserve the anterior capsule. The head of the capitate was then removed. The cut should be level with that of the scaphoid.

In cases of protuberant radial styloid osteophytes, a partial styloidectomy was performed with the oscillating saw.

The radial fossa was smoothed with the ovoid burr to remove the crest between the scaphoid fossa and the lunate fossa to obtain a homogenous concave ovoid surface along both axes. On the carpal side, the new midcarpal joint was smoothed and reamed to obtain a perfectly smooth and slightly concave sliding surface.

Any large dorsal and volar radial osteophytes were excised taking care to preserve the ligament attachments. The synovectomy was completed, and any tears in the volar capsule 

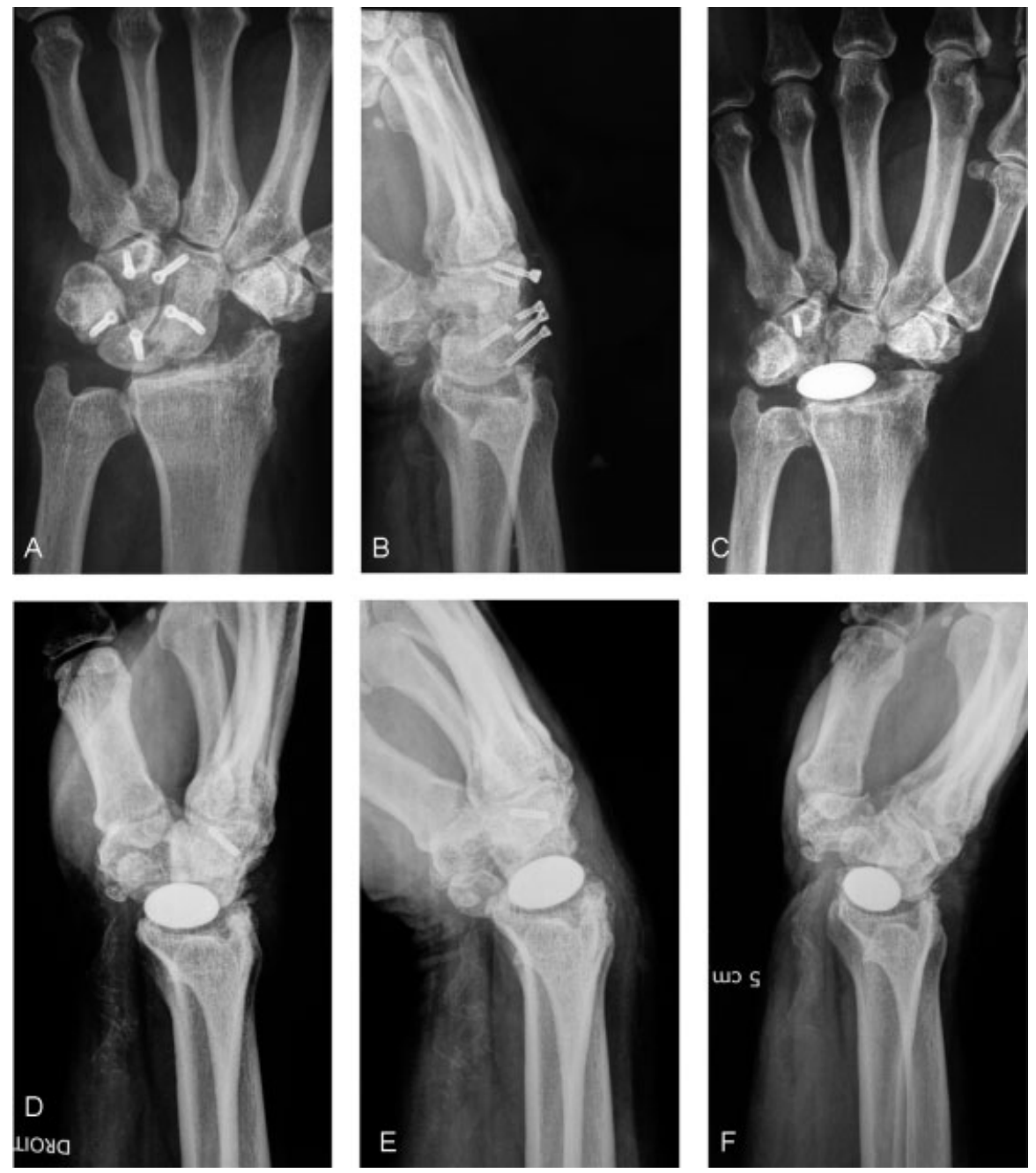

Figure 1 Four-bone fusion failure in the right wrist of a 66-year-old man. (A, B) preoperative X-rays. (C-F) postoperative standard and dynamic Xrays at 1 -year follow-up.

were repaired. A redundant volar was plicated with nonabsorbable sutures. Any large bone cavities in the radius or the carpus were curetted and bone grafted.

The size of the implant was assessed preoperatively with transparent tracings. The final size was determined intraoperatively, although the trial implant was in place ensuring that there was full passive flexion extension and full radial/ ulnar deviation, the implant did not tend to rotate on its proximodistal axis, which would otherwise indicate excess length or a lateral impingement through a cam effect, and the implant did not tend to subluxate volarly or dorsally, which would indicate lack of radial congruency, too little thickness, insufficient radial concavity, or redundant anterior capsule. The distal carpal row did not dorsally subluxate due to a torn or deficient capsule, and the distance between the ulna and the triquetrum were unchanged in comparison with the preoperative radiographs since this indicated a lack of excess implant thickness, and there was no impingement between the radial styloid and the scaphoid.

Additional procedures in our series included the following: removal of surgical material in 13 patients (silicone implants, circular four-bone fusion plate, shape memory staples, and screws), bone grafting of carpal cysts in 8 cases, and treating an ulnocarpal impingement in 2 cases (one Wafer procedure and the other partial triquetrum resection).

If the dorsal capsule was insufficient secondary to the multiple previous operations, it may be reinforced with a half of the extensor retinaculum flap slipped under the extensor tendons. This procedure was performed in three of our cases.

Postoperatively, the wrist was immobilized in neutral for 15 days, followed by gentle home motion exercises. A protective splint was worn during the night and during the day for comfort until the fourth week postoperatively, at which time, formal therapy was started if necessary. Unrestricted activity was allowed after 6 weeks.

\section{Clinical Data}

All measurements were performed on both operated and contralateral wrist.

Two self-administered questionnaires were used to assess functional scores: the Patient-Rated Wrist Evaluation (PRWE) and the QuickDASH (Disability Arm Shoulder and Hand). ${ }^{15,16}$ 

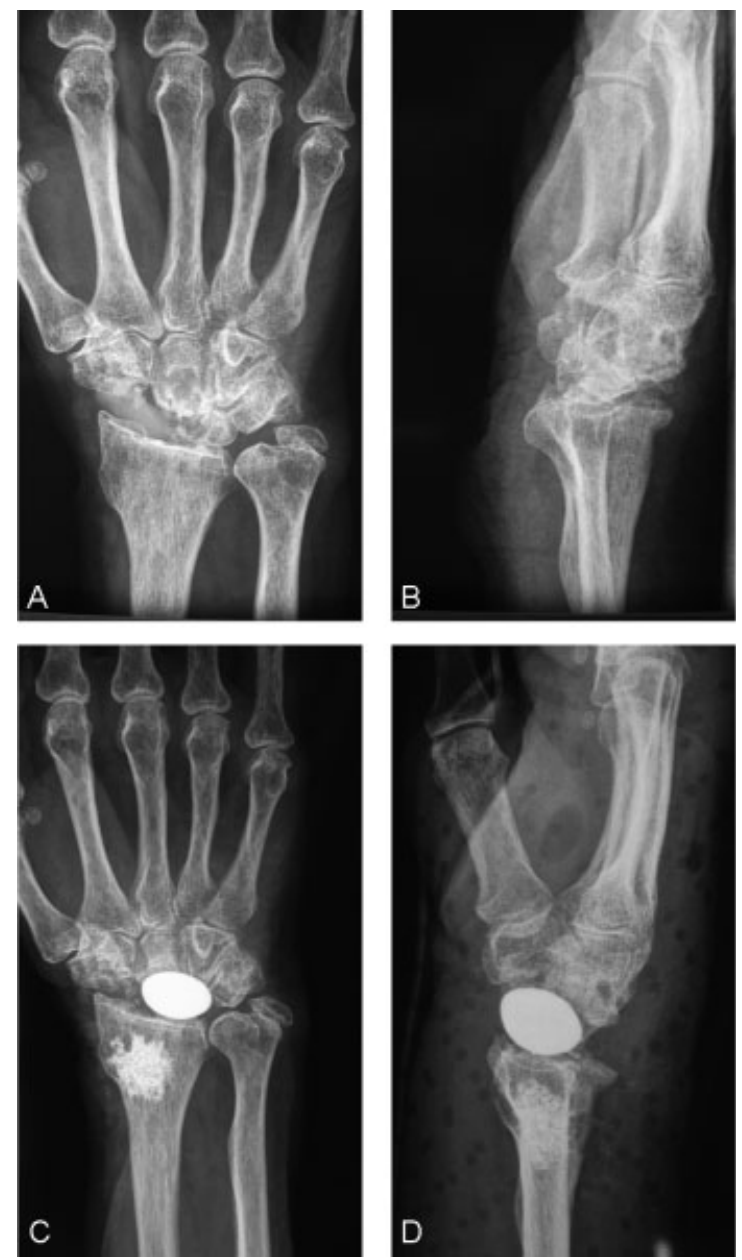

Figure 2 Scaphoid silicon implant failure after 15 years in the left wrist of a 71-year-old lady. (A, B) preoperative X-rays. (C, D) postoperative X-rays at 3-year follow-up. Carpal bone cysts have been filled with cancellous bone graft from the radius. Range of motion was 60 degrees in flexion extension and 40 degrees in ulnoradial inclination. Grip strength was $88 \%$ to the contralateral side, PRWE score was 3 of 100, QuickDASH score was 9.09 of100, and the patient was very satisfied. PRWE, Patient-Rated Wrist Evaluation; DASH, Disability Arm Shoulder and Hand.
Pain was rated on a pain scale between 0 and 10 by extracting the pain score from the Visual Analog Scale pain scale of the PRWE questionnaire (of 50 points).

Satisfaction was rated very satisfied, satisfied, fairly satisfied, or unsatisfied.

For patients with a professional activity, the time lapse before returning to work was noted.

Pre- and postoperative radiological measurements were done on PA and lateral wrist radiographs including the head of the third metacarpal to assess:

1. Carpal sagittal subluxation measured on the lateral X-ray by the relation $D / L_{1}$, where $D$ is the distance between the axis of the radius and the axis of the third metacarpal and $L_{1}$ is the length of the third metacarpal.

2. Carpal radial deviation measured on the PA view by Shapiro's angle between the line from the distal ulnar aspect of the radius to the tip of the radial styloid and the line of the long axis of the second metacarpal. ${ }^{17}$

3. Ulnar carpal translation measured with the Youm index. ${ }^{18,19}$

4. The height of the carpus measured with the Mac Murphy and Youm index. ${ }^{19}$

The postoperative radiographs were also analyzed for bone reaction (lysis or periosteal reaction) or periarticular ossification and for the implant position (subluxation and subsidence).

\section{Statistical Analysis}

All data were analyzed (average, standard deviation [SD], median, maximum, minimum) and then compared. Excel (Microsoft) and Statistica (StatSoft, Tulsa, OK) were used. The paired Student $t$ test, the Wilcoxon test, and the Pearson correlation coefficient were used to compare data.

\section{Results}

The average range of motion was 32 degrees in extension and 36 degrees in flexion on the operated wrist at the last followup (-Table 1). The gain in extension was 1 degree but not

Table 1 Clinical Results

\begin{tabular}{|c|c|c|c|c|}
\hline & Preoperative Data (SD) & Postoperative Data (SD) & Difference & $p$ \\
\hline Flexion $\left({ }^{\circ}\right)$ & $35(12)$ & $36(13)$ & +1 & $>0.05$ \\
\hline Extension $\left({ }^{\circ}\right)$ & $32(21)$ & $32(9)$ & 0 & $>0.05$ \\
\hline Flexion extension ROM $\left({ }^{\circ}\right)$ & $\begin{array}{l}67(26) \\
54 \% \mathrm{CL}\end{array}$ & $\begin{array}{l}68(18) \\
55 \% \mathrm{CL}\end{array}$ & +1 & $>0.05$ \\
\hline Ulnar inclination $\left(^{\circ}\right)$ & $24(18)$ & $21(8)$ & -3 & $>0.05$ \\
\hline Radial inclination $\left({ }^{\circ}\right)$ & $10(7)$ & $15(6)$ & +5 & 0.02 \\
\hline Ulnoradial inclination ROM $\left({ }^{\circ}\right)$ & $\begin{array}{l}34(21) \\
61 \% C L\end{array}$ & $\begin{array}{l}36(10) \\
64 \% \mathrm{CL}\end{array}$ & 0 & $>0.05$ \\
\hline Pronation $\left({ }^{\circ}\right)$ & $75(7)$ & $78(5)$ & +3 & $>0.05$ \\
\hline Supination $\left({ }^{\circ}\right)$ & $69(11)$ & $74(5)$ & +5 & $>0.05$ \\
\hline Grip (kg) & $\begin{array}{l}17(9) \\
46 \% \mathrm{CL}\end{array}$ & $\begin{array}{l}19(10) \\
53 \% \mathrm{CL}\end{array}$ & +2 & $>0.05$ \\
\hline
\end{tabular}

SD, standard deviation; ROM, range of motion; $\mathrm{CL}$, contralateral. 
Table 2 Functional Results

\begin{tabular}{|l|l|l|l|l|}
\hline & Preoperative Data (SD) & Postoperative Data (SD) & Difference & $p$ \\
\hline PRWE pain score/50 & $34(7)$ & $19(9)$ & -15 & 0.00035 \\
\hline PRWE function score/50 & $24(9)$ & $14(10)$ & -10 & 0.0034 \\
\hline PRWE total score/100 & $57(14)$ & $33(17)$ & -24 & 0.00034 \\
\hline QuickDASH score/100 & $59(12)$ & $39(18)$ & -20 & 0.0022 \\
\hline
\end{tabular}

SD, standard deviation; PRWE, Patient-Rated Wrist Evaluation; DASH, Disability Arm Shoulder and Hand.

statistically significant. The average range of motion in flexion was comparable with the preoperative data.

The postoperative radial and ulnar deviation was not significantly different to the preoperative one. Radial deviation increased an average of 5 degrees and ulnar deviation decreased by 3 degrees.

The average pronation and supination improved by 7 degrees but this was not significant.

Postoperative grip strength was an average of $19 \mathrm{~kg}$ or $53 \%$ of the grip strength on the opposite side. The average increase in grip strength was $2 \mathrm{~kg}$, which was not statistically significant.

Pain improved from an average of three points from 7 of 10 , preoperatively, to 4 of 10 , postoperatively. The average postoperative pain score was 19 of 50 (minimum $=3$, maximum $=31, \mathrm{SD}=9$ ) (-Table $\mathbf{2}$ ). The improvement between pre-and postoperative scores was 15 points on average. This difference was very significant $(p=0.00035)$. The average postoperative total PRWE score was 33\% (4 to 64, SD = 17), namely an average decrease of 24 points. There was a significant improvement in the global score after the procedure $(p=0.0034)$.

The average postoperative QuickDASH score was 39 (9.09 to $68.18, \mathrm{SD}=18)$. The average decrease was of 39 points $(p=0.0022)$. The average score for each question improved significantly.

Patients were either very satisfied (nine patients), satisfied (six patients), or fairly satisfied (one patient) with the surgical outcome.

Among the 10 patients who were still professionally active, at the last follow-up 5 had resumed their work at the same position, 3 had changed positions, and 2 were still on sick leave.

The mean postoperative carpal sagittal subluxation was 0.07 ( 0 to $0.19, \mathrm{SD}=0.07$ ). The difference $(0.01)$ with the mean preoperative value was not significant (-Table $\mathbf{3}$ ).
The average radial deviation angle (Shapiro's angle) was 109 degrees after surgery (94 to 125 degrees, $S D=10$ degrees). The difference ( -6 degrees) with the preoperative measurements was significant.

The Youm index was on average 0.33 ( 0.17 to 0.55 , SD $=0.109$ ), which is within the normal values for this index. The difference with the average preoperative value was not statistically significant.

The average carpal height was $0.40(0.28$ to $0.5, \mathrm{SD}=0.06)$. The difference $(-0.02)$ with the average preoperative value was not statistically significant.

No migration or subsidence was observed at the final follow up, even in cases of bone cysts filled with cancellous bone grafts (-Fig. 2). No dislocation was observed.

In one patient, there was moderate palmar subluxation (below a third of the total implant width) in the neutral position radiographically, but this was not seen with motion studies (-Fig. $\mathbf{3}$ ).

There was one case of major palmar subluxation (half of the implant width). The implant position did not change over time and did not seem to alter the final clinical and functional results in these two cases.

Subchondral calcification around the implant was found in nine cases at the latest X-rays.

No periarticular ossification was observed.

There were no cases of infection. Two patients required repeat surgery.

In one case of a 38-year-old man with advanced Kienböck disease, the implant rotated 90 degrees on its proximodistal axis. This patient had undergone a radius osteotomy 13 years before. A repositioning of the implant with a repeat reaming of the radial fossa was required twice in this patient. At the last follow-up (36 months), the flexionextension range of motion was 70 degrees, grip strength was $80 \%$ of the opposite side, the PRWE score was 14.5 of

Table 3 Radiographic Results

\begin{tabular}{|l|l|l|l|l|}
\hline & Preoperative Data (SD) & Postoperative Data (SD) & Difference & $p$ \\
\hline Carpal sagittal subluxation & $0.08(0.09)$ & $0.07(0.07)$ & 0.01 & $>0.05$ \\
\hline Radial deviation & $115^{\circ}\left(7^{\circ}\right)$ & $109^{\circ}\left(10^{\circ}\right)$ & $-6^{\circ}$ & 0.039 \\
\hline Carpal ulnar translation & $0.29(0.04)$ & $0.33(0.109)$ & +0.04 & $>0.05$ \\
\hline Carpus height & $0.42(0.05)$ & $0.40(0.06)$ & -0.02 & $>0.05$ \\
\hline
\end{tabular}

SD, standard deviation. 

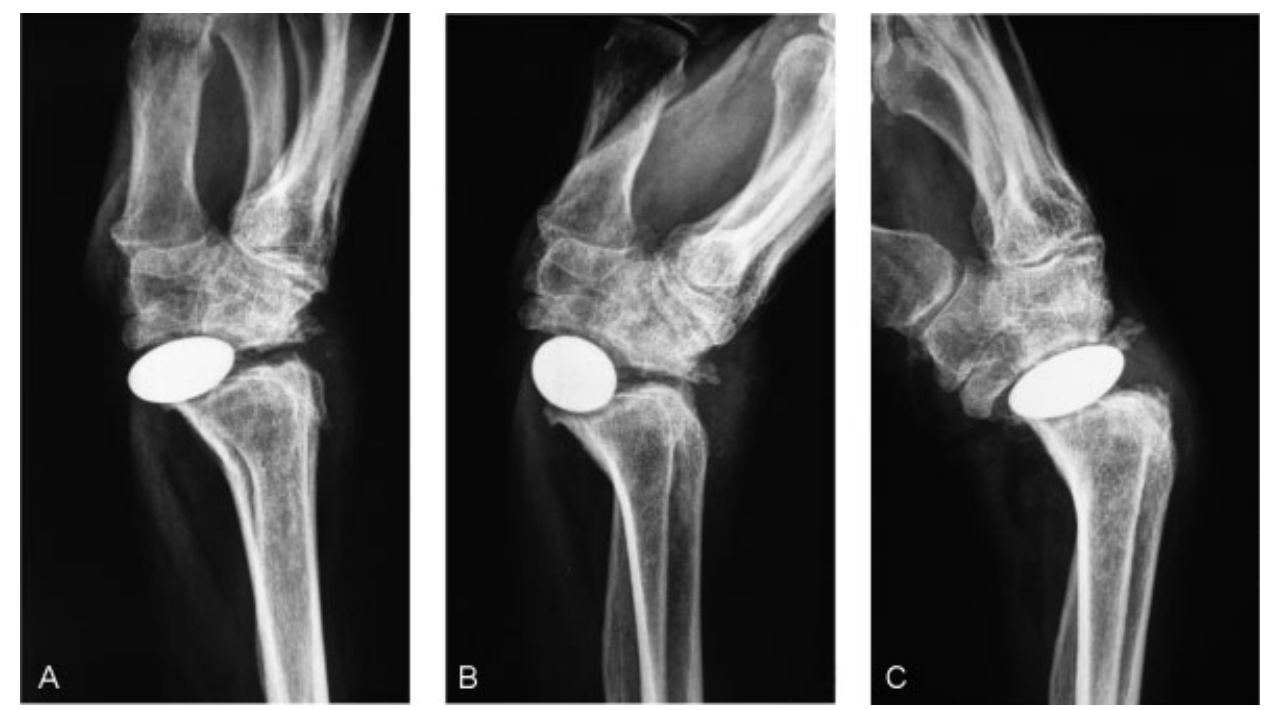

Figure 3 Anterior subluxation of the implant seen on the lateral view in neutral position. Relocation of the implant on dynamic radiographs. (A) neutral position; (B) extension; and (C) flexion.

100 , the QuickDASH score was 18.8 of 100 , and the patient was very satisfied.

In another case, a 52-year-old man had a failed four-corner fusion 8 years before. At 6 weeks, the implant was subluxated anteriorly and had rotated 90 degrees on its proximodistal axis. The implant was changed to a thinner one, the articular surfaces were reamed again, and a volar capsule was plicated with a micro anchor. At the 6-month follow-up, the patient was still recovering with decreasing pain and had not yet returned to work.

\section{Discussion}

The Amandys arthroplasty was used in this series as a salvage solution for mid-term or long-term failures of previous wrist surgeries of nonrheumatoid wrists. We did not use this arthroplasty in failed rheumatoid wrist surgery, because in most of these indications, the soft tissues, the carpal alignment, or the bone stock are not suitable.

The aim of this new arthroplasty is a pain free and mobile wrist. ${ }^{11}$ The lack of wrist motion is correlated with functional impairment to perform daily tasks and increases the perceived disability. ${ }^{20,21}$ Preserving wrist mobility is in fact the most important functional priority for patients along with pain relief. ${ }^{22,23}$ This new motion-preserving procedure was therefore proposed as an alternative to TWF, which could be in the past, the standard procedure for our patients, who were relatively young (aged 56 years on average) and most of them still working. Since we used the Amandys implant, we did not perform any more TWF in these indications.

Our preliminary results showed a functional improvement for all patients. The decrease in pain was the main factor for this. Range of motion was nearly on average the same as preoperatively and no patient lost mobility after the surgery. Average global strength increased but the improvement was not significant in comparison with preoperative data.
The implant was well tolerated clinically and radiographically. After the arthroplasty, the wrists remained correctly aligned without any anterior or posterior subluxation on the lateral view or ulnar deviation on the PA view. Radial deviation decreased significantly. This may explain the postoperative gain of 5 degrees in radial inclination and the postoperative loss of 3 degrees in ulnar inclination.

The implant did not subside and the carpal was maintained. The revision rate was low (12.5\%) and no implant removal or conversion to a total arthrodesis was required. Complications and the volar subluxation of the implant seen in two cases were mostly linked to technical errors in relation with the surgical learning curve of this new technique. These problems were related to the size of the implant, the evaluation of the anterior capsular distension, or the bone preparations.

The treatment reported in the literature for failed partial carpal arthrodesis, carpal silicone implant, first-row resection, or advanced Kienböck disease surgery is usually TWF. $^{24-29}$ TWF results are not always satisfactory. ${ }^{30,31}$ This procedure has complications and the results on pain and function, especially in patients with multiple surgeries are sometimes disappointing. ${ }^{31}$ Wrist motion preservation is the main advantage of the Amandys procedure compare with TWF. However, functional results should be compared in the future for the same indications.

The other options such as TWA are exceptionally proposed in these indications given the high risks of complications and revision in patients with high functional demands. ${ }^{32}$ The indications of TWA are limited to patients with low functional demand, usually rheumatoid arthritis patients, because the recommended maximum load allowed should be low. These restrictions do not apply to the implant in our series. Furthermore, the Amandys procedure is less invasive compared with a TWA. Bone and ligament resections are minimal. In cases of failure, TWF or TWA can be easily performed as 
salvage procedures. Because it is a free interposition, the Amandys procedure requires an efficient anterior and dorsal capsule to ensure both wrist and implant stability. Correct wrist alignment is mandatory as well. TWA does not imply such demanding restrictions and TWF even less.

According Mulford and coworkers' meta-analysis, the rates of conversion to TWF after a four-bone fusion or a first-row carpectomy are respectively 2.9 and $3.9 \% .^{33}$

Failures of four-bone fusions are often the consequence of nonunion due to bad technique or failure of the osteosynthesis material. A revision for a new arthrodesis is often possible. $^{34-36}$ When the lunate cannot be salvaged or that the radiolunate joint is degenerative, an interposition arthroplasty with a pyrocarbon implant has proven to be a good alternative to total arthrodesis (-Fig. 1). This arthroplasty is also possible in cases of failed first-row resections, ${ }^{11}$ which are more at risk for arthritic degeneration than four-corner fusions. $^{33}$

Failures after partial silicone implants are often due to silicone debris leading to foreign body synovitis and intracarpal bone cysts. Kaarela et al observed a $41 \%$ rate of this type of complication with lunate implants at 5.6 years follow-up. ${ }^{37}$ Vinnars et al had a $62 \%$ rate at 10 years follow-up for scaphoid implants $^{29}$ and Minami et al had a 33\% rate at 15.3 years follow-up with trapezial implants. ${ }^{38}$ Wrist arthrodesis is a salvage solution in cases of progressive symptomatic degeneration. The pyrocarbon interposition arthroplasty performed in five of our patients maintained useful wrist mobility and had a satisfactory functional outcome (-Fig. 2).

For both patients with advanced Kienböck disease who had had a prior radius shortening, the results were similar. Several technical points need to be highlighted to carry out this pyrocarbon interposition arthroplasty:

In revision cases of four-bone fusion, we recommend to be particularly careful about the anterior capsule distension in front of the lunate that is often in DISI position. Plicating or reinserting the capsule on the anterior edge of the radius prevents anterior subluxation or 90 degrees proximodistal rotation of the implant. The absence of the scaphoid did not increase radial implant deviation. The scaphoid space is filled with a fibrous scarring tissue that should be preserved.

In cases of failed first-row carpectomy, we recommend to check for a stylotrapezial impingement and to treat it subsequently with a radial styloidectomy.

In cases of failed silicone implant, complete synovectomy should be performed and the bone cysts facing the implant should be empty and filled with impacted cancellous bone (-Fig. 2).

The limitations of our study are its short follow-up and the limited number of patients in the series. Clinical and radiological studies on larger series with a longer follow-up will help determine the advantages of this arthroplasty and its specific indications in relation to arthrodesis indications. The small size of this arthroplasty and its minimally invasive procedure does not burn the bridge for a TWF in case of failure.

The Amandys interposition arthroplasty is a new therapeutic option in cases of difficult revisions procedures on the wrist. Preliminary results demonstrated that it is a reliable alternative to TWF. It is a salvage procedure that maintains wrist mobility and improves greatly pain and function in patients.

\section{Conflict of Interest}

Dr. Bellemère is a consultant agreement with TornierBioprofile (Grenoble, France). Occasional involvements include expert reports and advisory services (TornierBioprofile). Dr. Bellemere has attended conferences as contributor (Tornier-Bioprofile). Dr. Gaisne has attended conferences as audience member (Tornier-Bioprofile). Dr. Loubersac, Dr. Maes-Clavier, Dr. Kerjean, and Dr. Collon have no conflict of interest to disclose.

\section{References}

1 Ollier LXEL, ed. Traité des résections et des opérations conservatrices qu'on peut pratiquer sur le système osseux [in French]. Volumes 1 et 2. Paris, France: Masson; 1889

2 Fitzgerald JP, Peim CA, Smith RJ. Distraction resection arthroplasty of the wrist. J Hand Surg Am 1989;14(5):774-781

3 Tillmann K, Hansens C. Resection interposition arthroplasty of the wrist in rheumatoid arthritis. In: Simmen BR, Hagena FW, eds. The Wrist in Rheumatoid Arthritis. Basel, Switzerland: KARGER; 1992: 214-215

4 Skoff H. Palmar shelf arthroplasty, the next generation: distraction/interposition for rheumatoid arthritis of the wrist. Plast Reconstr Surg 1999;104(7):2068-2072, discussion 2073

5 Cook SD, Beckenbaugh RD, Redondo J, et al. Long-term follow-up of pyrolitic carbon metacarpophalangeal implants. J Bone Joint Surg Am 1999;81:930-939

6 Pequignot JP, D'asnieres de Veigy L, Allieu Y. Implant adaptatif du scaphoïde proximal [in French]. Chir Main 2000;2:276-285

7 Péquignot JP, Lussiez B, Allieu Y. Traitement de l'arthrose STT par un implant en pyrocarbone [in French]. Chir Main 2005;24: 148-152

8 Pegoli L, Zorli IP, Pivato G, Berto G, Pajardi G. Scaphotrapeziotrapezoid joint arthritis: a pilot study of treatment with the scaphoid trapezium pyrocarbon implant. J Hand Surg [Br] 2006;31(5): 569-573

9 Bellemère P, Ardouin L. Pi2 spacer pyrocarbon arthroplasty technique for thumb basal joint osteoarthritis. Tech Hand Up Extrem Surg 2011;15(4):247-252

10 Ardouin L, Bellemère P. A five-year prospective outcome study of Pi2 pyrocarbon arthroplasty for the treatment of thumb carpometacarpal joint osteoarthritis. Chir Main 2011;30(Suppl):17-23

11 Bellemère P, Maes-Clavier C, Loubersac T, Gaisne E, Kerjean Y. Amandys ${ }^{\circledR}$ implant: Novel pyrocarbon arthroplasty for the wrist. Chir Main 2012; In press.

12 Berger RA. The anatomy of the ligaments of the wrist and distal radioulnar joints. Clin Orthop Relat Res 2001;383:32-40

13 Moritomo H, Apergis EP, Herzberg G, Werner FW, Wolfe SW, Garcia-Elias M. 2007 IFSSH committee report of wrist biomechanics committee: biomechanics of the so-called dart-throwing motion of the wrist. J Hand Surg Am 2007;32(9):1447-1453

14 Berger RA. A method of defining palpable landmarks for the ligament-splitting dorsal wrist capsulotomy. J Hand Surg Am 2007;32(8):1291-1295

15 Voche P, Dubert T, Laffargue C, Gosp-Server A. [Patient-rated wrist questionnaire: preliminary report on a proposed French version of a North American questionnaire designed to assess wrist pain and function]. Rev Chir Orthop Repar Appar Mot 2003;89(5):443-448 
16 Dubert T, Voche P, Dumontier C, Dinh A. [The DASH questionnaire. French translation of a trans-cultural adaptation]. Chir Main 2001;20(4):294-302

17 Shapiro JS. A new factor in the etiology of ulnar drift. Clin Orthop Relat Res 1970;68:32-43

18 Youm Y, McMurthy RY, Flatt AE, Gillespie TE. Kinematics of the wrist. I. An experimental study of radial-ulnar deviation and flexion-extension. J Bone Joint Surg Am 1978;60(4):423-431

19 McMurtry RY, Youm Y, Flatt AE, Gillespie TE. Kinematics of the wrist. II. Clinical applications. J Bone Joint Surg Am 1978;60(7): 955-961

20 Adams BD, Grosland NM, Murphy DM, McCullough M. Impact of impaired wrist motion on hand and upper-extremity performance. J Hand Surg Am 2003;28(6):898-903

21 Sauerbier M, Kluge S, Bickert B, Germann G. Subjective and objective outcomes after total wrist arthrodesis in patients with radiocarpal arthrosis or Kienböck's disease. Chir Main 2000;19(4): 223-231

22 Laulan J, Bacle G, de Bodman C, et al. The arthritic wrist. II-the degenerative wrist: indications for different surgical treatments. Orthop Traumatol Surg Res 2011;97(4, Suppl):S37-S41

23 Adey L, Ring D, Jupiter JB. Health status after total wrist arthrodesis for posttraumatic arthritis. J Hand Surg Am 2005;30(5):932-936

24 Bain GI, Watts AC. The outcome of scaphoid excision and fourcorner arthrodesis for advanced carpal collapse at a minimum of ten years. J Hand Surg Am 2010;35(5):719-725

25 Ferreres A, Garcia-Elias M, Plaza R. Long-term results of lunocapitate arthrodesis with scaphoid excision for SLAC and SNAC wrists. J Hand Surg Eur Vol 2009;34(5):603-608

26 Richou J, Chuinard C, Moineau G, Hanouz N, Hu W, Le Nen D. Proximal row carpectomy: long-term results [in French]. Chir Main 2010;29(1):10-15

27 DiDonna ML, Kiefhaber TR, Stern PJ. Proximal row carpectomy: study with a minimum of ten years of follow-up. J Bone Joint Surg Am 2004;86-A(11):2359-2365
28 Croog AS, Stern PJ. Proximal row carpectomy for advanced Kienböck's disease: average 10-year follow-up. J Hand Surg Am 2008;33(7):1122-1130

29 Vinnars B, Adamsson L, af Ekenstam F, Wadin K, Gerdin B. Patientrating of long term results of silicone implant arthroplasty of the scaphoid. Scand J Plast Reconstr Surg Hand Surg 2002;36(1):39-45

30 Gaisne E, Dap F, Bour C, Merle M. [Arthrodesis of the wrist in manual workers. Apropos of 36 cases]. Rev Chir Orthop Repar Appar Mot 1991;77(8):537-544

31 De Smet L, Truyen J. Arthrodesis of the wrist for osteoarthritis: outcome with a minimum follow-up of 4 years. J Hand Surg [Br] 2003;28(6):575-577

32 Adams BD. Complications of wrist arthroplasty. Hand Clin 2010;26 (2):213-220

33 Mulford JS, Ceulemans LJ, Nam D, Axelrod TS. Proximal row carpectomy vs four corner fusion for scapholunate (SLAC) or scaphoid nonunion advanced collapse (SNAC) wrists: a systematic review of outcomes. J Hand Surg Eur Vol 2009;34(2): 256-263

34 Vance MC, Hernandez JD, Didonna ML, Stern PJ. Complications and outcome of four-corner arthrodesis: circular plate fixation versus traditional techniques. J Hand Surg Am 2005;30(6):1122-1127

35 Skie MC, Gove N, Ciocanel DE, Smith H. Management of non-united four-corner fusions. Hand (NY) 2007;2(1):34-38

36 Unglaub F, Manz S, Leclère FM, Dragu A, Hahn P, Wolf MB. Clinical outcome of rearthrodesis in cases of non-union following four-corner fusion. Arch Orthop Trauma Surg 2011;131(11): 1567-1572

37 Kaarela OI, Raatikainen TK, Torniainen PJ. Silicone replacement arthroplasty for Kienböck's disease. J Hand Surg [Br] 1998;23 (6):735-740

38 Minami A, Iwasaki N, Kutsumi K, Suenaga N, Yasuda K. A long-term follow-up of silicone-rubber interposition arthroplasty for osteoarthritis of the thumb carpometacarpal joint. Hand Surg 2005;10 (1):77-82 